\title{
EL PAPEL DE MANUEL TOUSSAINT EN EL FOLKLORE
}

\author{
$\mathbf{P} \mathbf{O} \mathbf{R}$
}

\section{VICE N T E T. M E N D O A}

A riqueza de erudición, las múltiples lecturas, el espíritu siempre ávi$\perp$ do, siempre alerta, dispuesto a toda clase de asimilación hicieron que Manuel Toussaint desde sus años mozos encausara su curiosidad hacia el campo del Folklore, bajo la atinada dirección del maestro don Pedro Henríquez Ureña, hacia los años de 1913, 14 y 15, en la Escuela de Altos Estudios de nuestra Universidad y asistiera a una cátedra de Folklore General en unión de Antonio Castro Leal y Alberto Vázquez del Mercado, empeñándose en recolectar para futuras empresas coplas de nana, arrullos, rimas de escolares, trabalenguas, pegas y burlas, juegos infantiles, romances, canciones, adivinanzas y aun modismos del lenguaje popular.

Aunque no hizo gran acopio de coplas y cantares por parecerle "flamenquismo de barrio", en cambio, reunió versiones de romances tradicionales como los de "Delgadina", "Las señas del marido", "Don Gato", "El payo", "Mambrú", "Alfonso XII", y el siguiente que me parece de una gran originalidad:

- ¿Vive aquí un tal don Facundo que ha poco murió, señora?

-No vive aquí, que ya mora ... _- En dónde?- En el otro mundo.

- ¿Y está muy lejos de aquí? - Más allá de Santa Fe.

- ¿Cómo lo podré encontrar? - Arrojándose usté al mar.

-Muchas gracias. - No hay de qué.

Que recogió en Santa Clara, Michoacán, de labios de Francisco Castrejón, en 1916. 
Entre las obras que consultó sobre la materia están, además de folkloristas franceses, las de Fernán Caballero, Rodríguez Marín, La Fuente y Alcántara, Menéndez Pidal y la "Reseña Histórica del Folklore", de Alejandro Guichot y Sierra.

Henríquez Ureña encontró en su discípulo un elemento magnifico para sembrar sus enseñanzas consistentes en la recolección, ordenación, comparación y clasificación de materiales genuinamente folklóricos, puesto que en la formación profesional, manifestada al través de su vida, siempre tuvo en mente el valor de la tradición popular; exteriorizó de varias maneras lo que aprendiera, produciendo artículos y estudios sobre temas como los siguientes: "La canción de Mambrú", "Folklore de Puebla y poblano", "El Libro de las charrerias", de don Luis G. Inclán, con la historia del caballo "Chamberi" y el "Reglamento de Gallos", la novela "Astucia", del autor citado, menospreciada por todos antes de que Toussaint la vindicara como literatura popular; "El arte popular en México", "La comida típica de México" y otros tantos que fluian de su pluma y estaban a punto de brotar, siempre con la seguridad, naturalidad, espontaneidad y elegancia con que él sabía hacerlo, poniendo de relieve, además, su perfección de hablista.

Folklore histórico. La canción de Mambru. ${ }^{1}$

Hay que reconocer que Manuel Toussaint fue el primero en México que abordó estos temas de cultura tradicional, escribiendo y publicando sus investigaciones. En efecto, hasta que él lo hizo, nadie se atrevia a tratar estos tópicos, mirándolos con desdén o no considerándolos dignos de atención. No obstante, el título marcaba ya un nuevo derrotero en los estudios literarios del país. Según las enseñanzas de Henriquez Ureña, no solamente la literatura clásica y de elevación debería estudiarse, sino también las manifestaciones que circulaban de boca en boca entre el pueblo, ya fuera de Francia, España o México, en este caso la canción burlesca de "Mambrú" o sea la del duque de Marlborough, usada entre nosotros por los niños y diseminada por todo el territorio, alcanzando por el Norte hasta Nuevo México, Estados Unidos.

El mérito del trabajo consiste en haber hurgado en los origenes hasta fijar cómo principió a ser conocida entre el pueblo de Francia, rememorando la batalla de Malplaquet, a principios del siglo xvin, habiendo sido ganada realmente por el satirizado duque. Toussaint expli- 
ca cómo estaba bien divulgada por Francia, puesto que la nodriza del Delfín "madame Poitrine", la cantaba como arrullo al infortunado príncipe, haciendo al mismo tiempo las delicias de María Antonieta. Luego cómo era aprovechada por los escritores y artistas; pero aún más, cómo a su vez derivaba de otro canto francés más antiguo: "El convoy del Duque de Guisa".

Para el Folklore de México, el servicio prestado por Toussaint consiste en haber iniciado el estudio de un tema tradicional que, pasando por España vino a México, también a finales del xviII con las alusiones que se le hacían al virrey Manuel Flores llamándole: "El Malbrucito". A nuestro interés concierne además el haber podido obtener variantes numerosas de la canción, texto y música, lo mismo en España que en nuestras diversas entidades, pudiendo asegurarse que se trata de un tema tradicional auténticamente folklórico.

\section{Folklore de Puebla y poblano. ${ }^{2}$}

Husmeador de viejos infolios y manuscritos, encontró entre los historiadores de Puebla, datos sobre pormenores de la Angelópolis, conventos de monjas, vida ciudadana, etc., y del mismo modo en la Puebla Sagrada y Profana, de fray Juan de Villa Sánchez, leyendas locales principiando por la de la fundación de la ciudad, trazada por los ángeles.

El articulista hace hincapié en la rivalidad de Puebla con México, la que dio lugar a multitud de coplas satíricas, de burla o de escarnio que ponen a los poblanos por el suelo, o en loa de sus cualidades. Su curiosidad lo llevó, con instinto de bibliófilo, a consultar una de las más interesantes obras que se hayan escrito sobre ciudad alguna: "Libro Nuevo de todas las cosas y otras muchas más, etc., etc.", que incluye alusiones a los poblanos, que presta importante servicio al folklore por lo que a los habitantes del país y su manera particular de ser se refiere, destacándose en primer lugar una parodia intitulada "Doctrina Poblana", un soneto que es una síntesis de cuanto hay de criticable en la ciudad; refranes aplicados, coplas improvisadas de "El Negrito Poeta", pasquines y una multitud de hojas sueltas impresas todas referentes a Puebla, en que aparecen glosas, décimas, valonas, cuándos, testamentos, jarabes, sones y canciones, entre otras: "La cachucha de las poblanas", fechada en 1844.

$\mathrm{El}$ interés demostrado por todas estas manifestaciones dedicadas a una sola ciudad indican que quien con tanto cariño las estudió sentía 
verdadera vocación por todos estos menesteres que dan la tónica folklórica en cuanto a costumbrismo.

\section{El Libro de las Charrerias. ${ }^{3}$}

Atento siempre a los temas de arte, ya pictóricos, ya literarios, ya de manufactura popular, para la serie: "Biblioteca Mexicana", que edita la Casa Porrúa Hermanos, Manuel Toussaint escribió un prólogo a la obra intitulada "El Libro de las Charrerías", de Luis G. Inclán, que incluye los siguientes trabajos: "Reglas con que un colegial pueda lazar y colear", "Recuerdo del Chamberí", "El capadero en la Hacienda de Ayala", "Don Pascasio Romero" y "Ley de Gallos".

Tal cantidad de elementos despertó en nuestro prologuista el mayor entusiasmo que lo impulsó a escribir un bien perfilado artículo sobre la personalidad de Inclán en su oficio de caballista, conocedor del medio rural de México hasta en sus menores detalles. Los comentarios al autor, minuciosos y entretenidos, pintan al mismo tiempo la vida campesina del México de mediados del siglo xIx.

El folklore de México ganó una considerable cantidad de noticias verídicas, no sólo en lo tocante a la profesión de charro, amansador o jugador de gallos, sino un copioso vocabulario perfectamente enfocado en las costumbres campesinas de los alrededores de la capital de la República, el Estado de México y de casi todo el pais. Sirvan de ejemplo las Décimas de don Pascasio Romero, en las que aparecen las cualidades de las bestias de montar con una riqueza de términos abrumadora.

Por lo que respecta a la "Ley de gallos", que como tal, se alejaría del folklore, tiene como el trabajo anterior, una serie de notas completamente folklóricas, explicando los términos usados en la gallería de México.

Las obras comentadas en el prólogo vienen a ser piezas escogidas de la literatura popular salida de una de las imprentas de México destinadas a este género: la del mismo Inclán, en la calle de San José El Real. Lo mismo puede decirse sobre el "Arte de colear y lazar" como reglas para que un colegial lo pueda hacer y los "Recuerdos del Chamberi", historia de este célebre caballo, escritos, como dice su autor, "con palabras del dialecto ranchero", único que conocía o lo que es lo mismo, en "pura habla popular", que es lo que al folklore le interesa. 
Astucia, El Jefe de los Hermanos de la Hoja o. Los Charros contrabandistas de la Rama.

Dadas las innumerables lecturas clásicas y la amplísima preparación literaria de Manuel Toussaint constituye, en nuestro ambiente de hace dos décadas, un caso raro de crítico que acepta y vindica como un buen ejemplo de literatura popular, entre las publicaciones de obras de Inclán, ésta, declarando que "si se toma la literatura en un sentido más amplio y humano, buscando en ella no sólo un arte de arreglo y acomodo, sino la expresión de la misma personalidad, sin aliño ni rebuscamiento (es decir, con las características que pide el folklore) Inclán es de los mejores literatos", y señala como cualidades en su obra el crear un vocabulario propio, el uso de expresiones y términos del pueblo de México en tal forma adecuada y precisa, que los filólogos espigan en sus obras términos $y$ giros peculiares de este país, es decir, los mexicanismos.

En lo que a la novela "Astucia" se refiere, además de las cualidades literarias de la obra y del lenguaje que emplean los protagonistas, el prologuista hace notar que debido al conocimiento profundo que el autor tiene en todas las cosas relativas a charrerías, su novela viene a ser la más vivida, la más interesante que se puede encontrar en el género. Es decir, reconoce que el costumbrismo mexicano, el folklore, proporciona a la literatura del país ingredientes puros y alquitarados que le han dado color y personalidad.

\section{Arte Popular de México. ${ }^{4}$}

Otro aspecto de folklorista que aparece en la obra de Manuel Toussaint está conectado con sus actividades de historiador y crítico de arte; pero derivándolo al arte popular. Esto se manifiesta en su artículo que sirve de epígrafe a este parágrafo que apareció en MExico × LA CULTURA, obra de síntesis que cerró el período de gobierno del general Avila Camacho. En esta ocasión el autor se adentra en la esencia folklórica, definiendo las manifestaciones populares como signo de antiacademismo, como parte del folklore $\mathrm{y}$ como arte no oficial; reconoce además que el arte popular es de todos los tiempos, es decir, tradicional. Hace notar cómo el pueblo no tiene el propósito deliberado de hacer arte, sino de 
llenar una función en su vida, cumpliendo una misión utilitaria y al mismo tiempo subconsciente, para lo cual pide, como en el arte clásico tres cosas: Creador, Obra y Contemplador. Principia por hacer una triple división en secciones en vista de nuestra realidad mexicana:

I. Supervivencias indigenas.

II. Imitaciones del arte no popular (o sea el erudito).

III. El verdadero arte popular mexicano.

El análisis que realiza lo divide lógicamente en Artes Mayores y Menores: Arquitectura. En ésta estudia las iglesias provincianas, las casas rurales en el Istmo de Tehuantepec, las de vecindad de diversas ciudades, que es lo mismo que hacer el estudio de la vivienda de las diferentes clases sociales que atañen al folklore.

Escultura. En ésta señala como figuras prominentes las imágenes de Santiago y San Isidro Labrador, relacionándolas con la guerra y la agricultura; luego menciona los objetos de apariencia humilde: saleros de piedra, mangos de cuerno, de cuchillos y navajas, horquetas en figura de animales para flechas de resorte, y el arte manual que se produce en las prisiones: cocos labrados, nueces, huesos de durazno, etc., con miniaturas talladas.

Pintura. Alude a los exvotos de madera, lámina, cartón, etc., ponderando las soluciones plásticas tanto en el dibujo como en el colorido y la perspectiva.

Entre las Artes Menores pone en primer lugar a la cerámica, clasificándola por sus características de color, forma y vidriado; agrupándolas según las diversas regiones productoras: México, Puebla, Guanajuato, Jalisco, Michoacán, Guerrero, Oaxaca. Las artes textiles son observadas especialmente en lo que toca a los sarapes y rebozos, especificando éstos por sus colores y procedencias, así como por su calidad. En la orfebrería detalla los llamados "milagros", de plata o de oro, en figuras de miembros humanos o de animales y hace hincapié en las ciudades en donde la labor es más meritoria.

Describe los diferentes tipos de lacas, origen y decoración, tanto las de Uruapan en Michoacán, como las de Olinalá, Gro., o Chiapa de Corzo. El mobiliario que estudia o sea el de las clases humildes de las ciudades 
- el provinciano, aparece representado por piezas de madera blanca, mesas, trasteros, cajas laqueadas, sillas de tule y señala además su procedencia. Lo mismo hace con la juguetería popular de barro, cartón, madera, hoja de lata, tule, carrizo, palma, papel, etc., describiendo sus formas y factura.

Es decir, que como conocedor del arte clásico de México, se emocionaba además con las manifestaciones tradicionales de nuestro pueblo, y como individuo educado en las disciplinas folklóricas, hacía verdaderas clasificaciones, mencionaba los rasgos distintivos, las procedencias por grupos regionales, por formas y colores, por la decoración y caracteres, elevando el arte popular a una categoría que antes no le era concedida.

\section{Pipiolo cn el Bosque de Chapultepec. ${ }^{5}$}

La literatura infantil. acaba de verse enriquecida con una nueva aportación: Las aventuras de Pipiolo en el Bosque de Chapultepec que, como los manuscritos de Cide Hamete Benengueli ha aparecido por casualidad. Es la literatura en general la enriquecida y más especialmente la de ficción, la de fantasía, los cuentos que hemos considerado siempre como de maravilla; todo aquello que saliendo de las proporciones normales de la vida, por su misma índole despierta el interés de los lectores de cualquiera edad, transportándoles a las edades de oro de la humanidad o a las pueriles del individuo.

La literatura general ha hecho esta adquisición porque, si bien es verdad que el relato a que se alude está dedicado a los niños, es bien sabido que estas narraciones alucinantes son gustadas por los adultos, entre más adultos mejor; como las películas de Walt Disney son saboreadas mejor por las personas grandes.

El paideuma infantil se ve ahora satisfecho con la publicación de la vida extraordinaria de Pipiolo, un niño empequeñecido por fuerzas desconocidas. Vida en la que todo es posible gracias a la mente infantil que todo lo resuelve y soluciona. Vida sorprendente en un ambiente moderno, capitalino de un bosque aristocrático de la capital mexicana; mas no por Eso menos fascinadora que la vivida por otros seres minúsculos de la literatura tradicional: Puck, Nils Holgersson, Pulgarcito, Almendrita, La Reina Mab y toda la sucesión de duendes, elfos, dwarfs, kobolds y otros tantos chanes, chaneques, chantiles, cuatetecos, niños rayos, vientecillos y tlaloques de la mitología europea o de la mexicana. 
De hoy más en adelante, la figura de Pipiolo será requerida por los párvulos en sus regalos de Navidad y Año Nuevo para sus horas de azueto o bien, en ediciones de lujo, con carátulas miniadas y cantos dorados existirá al lado del reflexivo que se retrae al recuerdo de su infancia, a los risueños márgenes de la niñez cuando vio pasar embelesado, navegando en una hoja de tilo a la simpar Almendrita al lado del Patito Feo, al Gato con botas junto a Guliver, atado por los liliputienses con hilo de araña.

$Y$ ésta fue una de las postreras hazañas literarias de Manuel Toussaint, quien tornando a su infancia, recordando sus lecturas fantásticas y el acervo de cuentos infantiles, quizo vivir a través de la historia de su héroe una serie de aventuras considerándose a si mismo quizá el protagonista. De cualquier manera este fue otro aspecto del folklore que entró dentro de sus facultades, aficiones y preparación para perpetuarlo en nuestra literatura infantil; no porque sea en si materia folklórica, sino por encerrar rasgos tradicionales de la narración mundial.

\section{Comida típica de México. ${ }^{\circ}$}

La última aportación al folklore que nos dejara el ilustre desaparecido, cuya labor en el campo de la sabiduría popular comentamos, fue ésta y en ella, como en las anteriores, puso a contribución cuanto aprendiera a través de sus viajes por el pais, por España y Europa para discernir aquello que nos es más peculiar sin perder su tradicionalidad. Al mismo tiempo en que realizara sus recorridos por las regiones del país más ricas en joyas artísticas, gustó siempre de saborear los platillos locales, las golosinas, los dulces, los guisos saturados con el olor y sabor de plantas que sazonan los antojitos mexicanos.

Toussaint tuvo a través de su vida la voluptuosidad de la mesa con minutas perfectamente graduadas, sabiamente combinadas, alternando los sabores, calificando las especias, los condimentos, los diversos ingredientes que han dado a nuestra cocina la fama de que disfruta, asi las cocinas poblana -la más sobresaliente-, la mexicana, la tapatia, veracruzana, oaxaqueña o yucateca; cada un en su debido lugar y con sus méritos propios, con sus aderezos también locales y regionales, sin desconocer lo que España ha aportado en cuanto a azafrán, gengibre, ajonjolí, orégano, tomillo, mejorana, laurel, anis, almendras, avellanas, pasas y aceitunas. 
Como en los trabajos ya reseñados, el autor ordena y clasifica y en esto estriba su aportación al folklore, pues al hacerlo pone en su verdadero sitio cada tema, comprobando de paso su tradicionalidad. Principia como buen conocedor de la materia indigena, con las comidas prehispánicas, mencionando variantes del pozole, tortillas, tamales y atoles; sigue con los vegetales a que se vieron obligados los indigenas por el ambiente y el suelo $y$ pone en lugar aparte las verduras comestibles de las yerbas, pues tienen lugar separado los aguacates, chayotes, nopales, etc., del epazote, quelites o quintoniles. Entre los animales usados en los guisos cita aves, reptiles, anfibios, peces, insectos y otros condimentos del mismo origen, que en ocasiones causan estupor a nuestros visitantes.

Aborda en seguida la comida actual, que es sin género de duda la más rica y multiforme; en la enumeración separa los mariscos de insuperable sabor, procedentes de nuestras costas, de los moles regionales: amarillos, negros o colorados. Se esmeró en el agrupamiento al señalar lo más característico que aportan tanto los Estados como las Regiones y aun ciudades de nuestro país, al hacer la descripción habla con verdadero entusiasmo, como si estuviera en el momento de saborear los diversos guisos y productos, asi enumera el tasajo de Chihuahua; los machitos y agujas de Monterrey; el menudo de Durango; la cochinita pivil y los huevos a la motuleña de Yucatán; de Chiapas, el queso, los jamones de San Cristóbal y el aguardiente comiteco; los tamales oaxaqueños; el pulque de los llanos de Apan y como complemento, los gusanos de maguey; de San Luis Potosí, el queso de tuna y mezcal; Jalisco, sobresale por el pozole, la birria, el tequila y el pollo en fiambre; Puebla por las chalupas; Cholula con sus exquisitas morcillas y morongas compuestas; Pátzcuaro contribuye con su pescado blanco; las producciones de Toluca son: chorizos, longanizas, chicharrones, entre sus bebidas, el mosco y la zarzamora; de Jalapa recomienda los frijoles negros refritos; de Yecapixtla, la cecina; de Texcoco, las carnitas y la barbacoa; la capital de la República participa con una larga serie de tortas, tacos, caldo de la "Indianilla", pipián, chilacayotes en lo mismo; revoltijo hecho con romeritos; el mole de pancita y los chiles en nogada. El capitulo de los quesos es igualmente variado, pues los hay de Chiapas, Toluca, añejo de la Barca, quesillos de Oaxaca, de San Fandila; del Cabrío de Tizapán, delicioso con panochitas; los de Chihuahua y los de Santa Bárbara.

Pondera las frutas del país como postre, mencionando entre los zapotes: el blanco, el prieto, el amarillo y sobre todo el chico zapote; lo mismo hace con la chirimoya, anona, mamey, pitahaya, tejocotes y los 
capulines. La sección de dulces, probablemente sea la más tradicional, pero con adaptaciones que han hecho en México las monjas de los diversos conventos. La enumeración es variada y en sí misma constituye un mosaico apetitoso: jalea, cocada, flan, leche de coco, conservas, compotas, mermeladas; camotes cubiertos, alfajores, empanadas de almendra, mazapanes, tortitas, xoconoxtles, confitados, pasta de pepita, cajeta de Celaya, jamoncillos de Lagos, chongos zamoranos, morelianas, cueros de membrillo; ates de guayaba, membrillo, durazno, de chirimoya; arrallanes de Guadalajara, frutillas de Querétaro, además, camotes, punche, calabaza en tacha, chacualole y una serie innumerable de variedades a cual más sugestiva.

Como parte de la comida diaria nos habla de las meriendas con enchiladas, pambacitos compuestos, tostadas, sopes, tamales, chocolate, champurrado o café con leche y bizcochos. A éstos les dedica una nutrida enumeración, la cual por sí sola constituye un capítulo de folklore alimenticio; para abreviar solamente mencionaré: chilindrinas, campechanas, limas, volcanes, alamares, chamucos, picones, huesitos de manteca, roscas de canela, nopales, colchones, trenzas, cocoles con ajonjoli, violines, ladrillos, pelucas, molletes, buñuelos, capitulados, chamberinas, chicharrones, chimisclanes, pambazos, teleras, birotes, espuelas, bollos, hojarascas empanadas, apasteladas, etc., etc.

Para concluir diremos qué labores más urgentes e imperiosas en pro del arte mexicano y su historia, le impidieron dedicarse, como hubiera deseado, al estudio de la materia folklórica. Fue uno de los miembros fundadores de la Sociedad Folklórica de México de la cual fue consultor constante; pero el índice que marca su estatura cultural fue el haber dado decidido apoyo a los estudios del folklore, manteniendo dentro del Instituto a su cargo, un puesto de Investigador, patrocinando viajes de exploracin a diversas partes del país $\mathrm{y}$ haber contribuído efectivamente a la representación de México en el Congreso Internacional de Folklore, celebrado en San Pablo, Brasil, en 1954, así como dando oportunidad al Investigador de su Dependencia para sustentar cátedras en diferentes universidades extranjeras, logrando de esta manera que México ocupara un lugar digno entre los países más avanzados que se dedican al estudio de esta materia. 